\section{Aneka Fungsi Bahasa Syair- Syair Lagu Ismail Marzuki}

I Dewa Putu Wijana

Fakultas IImu Budaya, Universitas Gadjah Mada Surel: idp_wijana@yahoo.com

\begin{abstract}
This article intends to reveal various language functions consisted in Ismail Marzuki's song lyrics in the frame of the widely known Jakobson's language function theory. By using data gathered from various sources, the research findings shows that Ismail Marzuki's song lyrics are dominated by the use of language which is exploited to bear poetic function in order to enable the audiences experiencing the song's messages and other language functions aesthetically. All Marzuki's song lyrics concern with extralinguistic world. Accordingly, it is not surprising that none of the song lyric is used to convey metalinguistic function for explaining the internal structure of a language.
\end{abstract}

Keywords: lyric, song, poetic, and language function

\title{
PENDAHULUAN
}

Ismail Marzuki adalah salah satu dari sejumlah komponis Indonesia yang mampu menciptakan banyak lagu, dan boleh dikatakan kebanyakan lagu-lagu ciptaannya memiliki nilai keabadian, dan tidak mudah dilekang jaman. Hingga sekarang misalnya, lagu-lagu ciptaan Ismail Marzuki masih sering terdengar dikumandangkan untuk berbagai kepentingan, terutama untuk hal-hal yang berhubungan dengan penggalangan solidaritas nasional. Misalnya baru-baru ini untuk aksi keprihatinan Ahok, konduktor Adi M.S. di depan masa pembela Ahok bersama Djarot Saiful Hidayat, mengumandangkan tiga buah lagu wajib, yang entah karena kebetulan atau tidak, dua di antaranya adalah lagu ciptaan komponis ternama ini, yakni "Indonesia Pusaka" dan "Rayuan Pulau Kelapa", dan satu lainnya adalah karya H. Mutahar, "Syukur". Tentu saja, ada berbagai hal yang menyebabkan keabadian lagu-lagu ciptaan Ismail Marzuki. Mulai dari hal-hal yang berkaitan dengan musikalisasi, tema lagu, sampai dengan kekuatan lirik lagu yang sampai sekarang sulit ditandingi oleh komponis lain. Sehubungan dengan ini, adalah di luar kemampuan, dan bukan bidang keahlian penulis untuk membicarakan kekuatan Ismail Marzuki dalam hal-hal yang berhubungan dengan seni musik. Makalah singkat ini hanya berusaha sekadar memberi ulasan yang berhubungan dengan berbagai fungsi bahasa yang cukup menonjol dan kurang menonjol dimanfaatkan oleh komponis di dalam menciptakan lagulagunya. Sejauh ini, belum ada usaha para ahli bahasa untuk mengamati masalah ini. Pembahasan mengenai almarhum dan berbagai karyanya memang telah ada yang melakukan. 
Misalnya karya Leksono [2014] membahas secara panjang lebar mengenai posisi karyanya setelah 100 tahun ditinggal komponisnya, perjalan hidupnya, lagu-lagu dan penciptaannya, melodi dan kritik-kritik yang dilontarkan. Sementara itu, analisis linguistik pernah dilakukan oleh [Yosa, 2016] berkenaan dengan metafora tentang "wanita" dalam karya-karya Ismail Marzuki. Kenyataan ini menunjukkan bahwa masih cukup terbuka lebar kesempatan bagi para ahli untuk mengeksplorasi karya-karya komponis besar ini dari aspek kebahasaan.

\section{LANDASANTEORI}

Bahasa sebagai alat komunikasi verbal manusia yang utama memiliki berbagai macam fungsi yang jenis-jenis serta jumlahnya mungkin tidak akan mampu diperikan oleh ahli-ahli bahasa. Ahli-ahli bahasa melakukan pembagian fungsi-fungsi bahasa secara berkesinambungan, mulai dari pembagian yang sederhana yang berporos pada dua fungsi, seperti "referential" dan "emotif" [Buhler, 1934] ; "transaksional" dan "interaksional" [Brown \& Yule, 1989, 1-2]; "ideational" dan "interpersonal" [Halliday, 1970]; "representatif dan ekspresif" [Jakobson, 1970]; "deskriptif" dan "sosial ekspresif" [Lyons, 1977]. Makalah ini akan menguraikan permasalahan dari sudut fungsi bahasa yang lebih kompleks yang dikemukakan oleh Jakobson [1966, 350-359] yang cukup luas dikenal di kalangan ahli bahasa dan sastra [Kadarisman, 2009, 53-54]. Dalam kerangka fungsi bahasa Jakobson, disebutkan sekurang-kurangnya 6 buah fungsi bahasa berdasarkan orientasi komunikasinya. Adapun keenam fungsi bahasa itu adalah fungsi "emotif" yang berorientasi pada "pengirim; "konatif" yang berorientasi pada "penerima"; "referensial" yang berorientasi pada "konteks", "puitik" yang berorientasi pada "pesan", fungsi "fatis" yang berorientasi pada "kontak", dan "metalinguial" yang berorentasi pada "kode bahasa". Dalam artikel itu, Jakobson secara tegas mengemukakan bahwa sangatlah mustahil bila di dalam sebuah komunikasi verbal hanya satu fungsi bahasa yang mengambil peranan. Akan tetapi, sebuah komunikasi verbal selalu saja akan melibatkan berbagai fungsi bahasa, hanya saja ada satu atau beberapa fungsi bahasa yang lebih menonjol daripada fungsi-fungsi yang lainnya. Pernyataan yang sama juga dikemukakan oleh Holmes [1995, 286-287]. Sehubungan dengan ini, tentu saja akan sangat bergantung pada genre wacana yang menjadi sarana atau saluran komunikasi itu. Sejajar dengan ini, genre wacana menurut kerangka teori Hymes [1974] merupakan salah satu komponen pertuturan yang cukup penting di dalam menentukan wujud bahasa yang digunakan oleh penutur, di samping 8 komponen lainnya, seperti scene, participant, end, act of sequence, key, instrumentalities, dan norm. Dari pernyataan Jakobson tersebut di atas dapat diasumsikan bahwa tentu saja ada fungsi-fungsi bahasa yang dominan, agak dominan, kurang dominan bahkan tidak hadir, di dalam wacana syair lagu Ismail Marzuki. Kesemua ini terjadi karena ada satu atau beberapa fungsi bahasa yang harus ditonjolkan. 
Tulisan ini akan mencoba menguak dominansi fungsi-fungsi bahasa itu beserta alasan-alasan yang mendasarinya.

\section{METODE}

Syair-syair lagu yang menjadi bahan analisis tulisan ini diperoleh dari buku-buku yang membahas karya Ismail Marzuki, buku kumpulan lagu wajib Indonesia, dan buku kumpulan lagulagu Ismail Marzuki. Analisis dilakukan dengan pembacaan secara berulang-ulang syair-syair lagu tersebut untuk mencapai pemahaman yang mendalam sehingga dengan memperhatikan berbagai kemungkinan konteks maksud pengutaraannya, fungsi-fungsi bahasa yang berperan di dalamnya dapat diungkapkan. Uraian akan dimulai dengan mengikuti alur model fungsi bahasa Jakobson, yakni mulai dari fungsi emotif, fungsi referensial, fungsi poetik, fungsi fatik, fungsi metalingual, dan diakhiri dengan fungsi konatif.

\section{HASIL DAN PEMBAHASAN}

Seperti yang telah dihipotesiskan ada 5 buah fungsi bahasa yang dimanfaatkan, dan kelimanya dimanfaatkan dengan intensitas yang berbeda-beda. Satu buah fungsi bahasa, yakni fungsi metalingual, fungsi untuk menerangkan bahasa tidak ditemukan di dalam syair-syair lagu Ismail Marzuki. Adapun hasil analisis kelima fungsi tersebut secara berturut-turut adalah sebagai berikut:

\section{Fungsi emotif}

Fugsi emotif atau fungsi ekspresif adalah fungsi bahasa yang digunakan oleh sang komponis untuk mengungkapkan berbagai perasaan, seperti perasaan sedih, perasaan rindu, perasaan kagum, gembira, dsb. Ungkapan perasaan sedih jelas terlihat dalam syair lagu "gugur bunga", "sapu tangan dari Bandung Selatan", dsb. Ungkapan perasaan rindu meliputi kerinduan akan bermacam-macam hal, seperti rindu akan kampung halaman, rindu kekasih, rindu tempat tertentu, dsb. Perasaan rindu kampung halaman terungkap dalam syair lagu "kampung halaman", "lambaian bunga", "jangan ditanya" dsb. Ungkapan perasaan ridu terhadap kekasih dapat dijumpai di dalam sejumlah syair lagunya, seperti "Aryati", "rindu lukisan", "kunang-kunang", "lambaian bunga", "Oh angin sampaikan salamku", dsb. Perasaan kagum sangat jelas terlihat pada lagu-lagu bernada pujian terhadap keindahan tanah air, seperti "rayuan pulau kelapa", "Indonesia pusaka", "lambaian bunga", dsb. Kekaguman terhadap ketampanan pria dan kecantikan seorang wanita terlihat dalam lagu "Kopral Jono", "Juwita malam", "sersan mayorku", dsb. Contoh [1] s.d. [4] berikut adalah penggalan lagu "gugur bunga", "kampung halaman", "kunang-kunang", "juwita malam yang secara berturut-turut mengungkapkan ekspresi kesedihan, kerinduan akan kampung 
kelahiran, kerinduan akan kekasih, dan kekaguman terhadap seorang wanita. Lambang [/] memisahkan baris, sedangkan [//] memisahkan bait.

[1] Betapa hatiku takkan pilu/telah gugur pahlawanku/betapa hatiku tak akan sedih/hamba ditinggal sendiri//Siapakah kini pelipur lara/ nan setia dan perwira/siapakah kini pahlawan hati/ pembela bangsa sejati.

[2] Di sana di balik awan/kampungku indah nian/tempatku kecil berkawan/tempat ayah bunda berdiam//Di sana taman bahagia/kampungku cantik nian/di sana aku bahagia/bebas bagai elang merdeka

[3] Kunang-kunang singgah dulu di pangkuanku/hiburkanlah hatiku nan dendam rindu/beta rindu kan teruna nan perwira/bawalah aku pada dia segera

[4] Engkau gemilang malam kemilau/bagaikan bintang timur sedang mengembang/tak jemu-jemu mata memandang/aku namakan dikau juwita malam.

Tentu saja dalam hal ini perlu dicatat bahwa seringkali atau mungkin semua syair-syair lagu Ismail Marzuki tidak hanya mengungkapkan satu macam perasaan saja, tetapi ada ada berbagai macam ungkapan perasaan di dalamnya. Misalnya, contoh [5] berikut adalah kutipan syair lagu "Aryati" yang mengungkapkan kerinduan, kekaguman, kesedihan, dan kebahagiaan bercampur menjadi satu:

[5] Aryati engkau mawar di taman khayalku/tak mungkin engkau terpetik daku/walaupun demikian nasibku/namun aku bahagia seribu satu malam.

Sementara itu, syair lagu "sampul surat" [6] berikut menggambarkan perasan gemblra diikuti dengan ungkapan kekecewaan, dan kesedihan:

[6] Betapa riang rasa hatiku/tak dapat kuceritakan/segera kubuka sampulnya/dengan penuh pengharapan//tetapi apa dayaku di kala itu kecewa/yang kutrima hanyalah sampul kosong belaka //Walaupun hatiku remuk redam/sampulnya kusimpan jua/agar jadi kenang-kenangan/selama hidup di dunia.

\section{Fungsi referensial}

Semua lagu tentu mengungkapkan makna referensial, tetapi fungsi bahasa ini tidak bersifat utama di dalam wacana syair-syair lagu yang lebih mengutamakan pengungkapan keindahan. Hal ini tidak menolak kemungkinan akan adanya syair lagu yang sangat sederhana sehingga amat mudah ditangkap maknanya. Sejumlah lagu dolanan anak-anak di dalam berbagai bahasa daerah yang berfungsi sebagai alat untuk memperkenalkan anak kepada berbagai hal di sekitar kehidupannya, akan lebih menonjol fungsi referensialnya dibandingkan fungsi emotifnya. Syair-syair lagu Ismail Marzuki cenderung lebih didominasi oleh fungsi pengungkapan yang bersifat ekspresif, alih-alih pengungkapan yang bersifat referensial. Sehubungan dengan ini, untuk memahami makna referensial apa yang ingin diungkapkan oleh lagu-lagu Ismail Marzuki yang bersifat ekspresif, syair-syair lagu itu harus 
diparafrasekan, dan hasil parafrasenya akan membuat wacana itu sama sekali kehilangan daya pikatnya. Coba perhatikan contoh [7] berikut yang merupakan pengungkapan referensial dari syair lagu "sampul surat".

[7] Sepuluh tahun yang lalu pagi-pagi aku mendapat surat. Surat dari temanku itu sudah lama aku tunggu. Hatiku senang sekali, lalu segera saja sampulnya aku buka. Tapi, aku sangat kecewa karena sampulnya kosong tidak ada isinya. Meskipun begitu, surat itu tetap aku simpan supaya aku terus ingat selama ini berteman dengan dia.

Pemahaman lewat parafrase ini pada hakikatnya merupakan analisis struktural sebagai langkah paling awal untuk memahami sebuah puisi sebelum melakukan analisis metaforis atau pun semiotik yang lebih rumit dan tinggi tatarannya karena bila semata-mata struktural, analisis tidak akan mencukupi [Pradopo, 2012, 127-167]. Hal ini disebabkan karena syair lagu memiliki sifat yang jauh berbeda dibandingkan dengan wacana-wacana yang semata-mata bertujuan untuk mengungkapkan informasi, seperti wacana ilmiah, wacana berita, dsb.

\section{Fungsi puitik}

Sesuai dengan genre wacananya, fungsi puitik bahasa sangat atau paling mendominasi syair-syair lagu Ismail Marzuki. Dengan fungsi bahasa ini ekspresi atau ungkapan hati komponis dapat diterima oleh para pendengar atau penikmatnya dengan rasa keindahan. Hal ini sesuai dengan pendapat Holmes [19995, 286] bahwa fungsi puitik adalah usaha pemanfaatan bahasa untuk menciptakan sesuatu yang bersifat estetik. Selain pada karya sastra, pemanfaatan fungsi bahasa ini juga kerap dimanfaatkan pada wacana iklan, sloganslogan, motto, dsb. Untuk mencapai hal ini, para penyair kerap kali melakukan berbagai usaha, seperti pemanfatan berbagai gaya bahasa [personifikasi, metafora, metonimia, simile, dsb.], penggunaan kata-kata ragam sastra, menciptakan berbagai pola persajakan [aliterasi dan asonansi], sampai dengan menyimpangkan gramatika dan makna bahasa dalam batas-batas tertentu yang lazim disebut "Licentia Poetica" [Wijana, 2017, 15-29]. Untuk memahami bagaimana fungsi ini dimanfaatkan coba diperhatikan syair lagu "jangan diatanya" [8[]berikut yang mengungkapan rasa kepedihan, kekecewaan, keputusasaan:

[8] Jangan ditanya ke mana aku pergi/jangan ditanya mengapa aku pergi/usah dipaksa tuk menahan diri/usah dipinta ku bersabar diri // Putuslah rambut putus jua ikatan/pecahlah piring hilang sudah harapan/ Hati nan rindu apakah sebabnya/hati nan dendam apakah obatnya //Pandai dikau mempermainkan lidah/menjual madu di bibir nan merah/kubayar tunai dengan asmara/kiranya dikau racun di lara //Jangan ditanya ke mana aku pergi/jangan disesal aku takkan kembali/tamatkan saja riwayat nan sedih/selamat tinggal kubermohon diri.

Syair lagu yang pernah dipopulerkan kembali oleh Muchsin pada tahun 1970-an ini memiliki berbagai elemen sebagai sarana pengungkap keindahan, seperti persajakan akhir: bait 
pertama a, a, a,a; bait kedua a,a,bb; bait ketiga: a,a, bb; bait keempat a,a,a,a. Jumlah suku kata dalam baris rata-rata 11 sampai dengan 12. Repetisi bait Jangan ditanya ke mana aku pergi; repetisi kata jangan, kata putus. Sebagai sarana pengungkap ketidaklangsungan puisi memakai berbagai gaya kata, seperti metafora putus rambut, putus ikatan, pecah piring untuk kegagalan cintanya; obat untuk menghilangkan atau mengatasi kemarahan dan kekecewaan; mempermainkan lidah untuk kepandaian berkata-kata; menjual madu untuk kata-kata dan janji indah yang diungkapkan; kubayar tunai untuk imbalan kata-kata atau janji itu; racun untuk penyebab semua kepedihan itu. Sebagian metafora itu juga difungsikan untuk pengungkapan hiperbola, seperti putusnya rambut dengan ikatan dan pecahnya piring dengan hilangnya harapan untuk mengekspresikan hubungan yang tidak mungkin dijalin kembali. Selain itu, lagu ini juga menggunakan leksikon-leksikon ragam indah, seperti dikau, aku, nan, jua, dan lara yang dalam ragam nonliterer diungkapkan dengan kamu, saya, yang, juga, dan sakit. Penyimpangan yang ditujukan untuk mencapai keselarasan irama dilakukan dengan pelesapan dan kontraksi, seperti atuk, ku, takkan, dan disesal dari bentuk lengkap untuk, aku, tidak akan, dan disesali atau disesalkan.

Sejumlah metafora syair-syair Ismail Marzuki memiliki daya ungkap yang imaginatif. Metafora-metafora yang diciptakan akan membawa angan-angan para pendengarnya, dan sebenarnya metafora itu tidak mungkin ada di dalam kenyataan. Metafora-metafora imajinatif ini biasanya dilukiskan akan membantu aku liris yang mengalami berbagai ketidakberdayaan.Yang paling umum adalah ketidakberdayaan bertemu dengan kekasihnya. Untuk ini berbagai ranah sumber digunakan, seperti angin, kunang-kunang, burung, kupu-kupu, dsb. Dalam syair lagu "kunang-kunang" [9] diceritakan aku liris meminta kabar tentang keberadaan dan keadaan kekasihnya, dan menghibur untuk mengobati rindu hatinya. Sementara itu, dalam penggalan bait-bait lagu "candra buana" [10] burung merpati dilukiskan secara imaginatif mambawa jawaban sang pemuda kepada kekasihnya yang cantik dan bijak dengan perlambangan metaforis bidadari dan putri bestari.

[9] Kunang-kunang kelana di rimba lara/dari manakah gerangan wahai tuan/kabar apakah nan dikau bawa tuan/hatiku tak sabar menanti jawaban // Kunang-kunang singgah dulu di pangkuanku/hiburkanlah hatiku nan dendam rindu/beta rindu kan teruna nan perwira/bawalah daku pada dia segera.

[10]Alam semesta berselubung sutra/kemilau cahaya sang candra/sejuta bintang kilauan/harum madu bunga di taman/merdu terdengar suara bidadari/merayu merajuk insani /candra buana ciptaan dewata/menjelang kasih asmara//dengarlah dengar jawaban sang teruna/ dari balik telaga warna/dibawa terbang merpati/ kepangkuan putri bestari..... 
Dalam penggalan bait sayair lagu "lambaian bunga" [11], bahkan digambarkan si aku liris ingin menjela menjadi seekor kupu-kupu karena sudah tidak tahan menanggung rindu terhadap tanah kelahiran dan kekasihnya:

[11] Air mataku titik berlinang/dusunku terkenang-kenang/hasratku ingin segra kembali pulang/kepangkuan ibundaku sayang/terasa betapa kurindu/akan bunga nan indah ayu/hasratku ingin segra menjelma kupu/terbang malam kujelang kasihku.

\section{Fungsi fatik}

Fungsi fatik adalah fungsi bahasa yang berpusat pada usaha penutur untuk menciptakan berbagai hubungan atau kontak dengan lawan bicaranya, mempertahankan kontak itu bila dibutuhkan, dan mengakhirinya. Setelah dilakukan pengamatan secara mendalam, syairsyair lagu Ismail Marzuki, berdasarkan relasi peserta pertuturannya atau sudut pandang pelibat wacananya, terdapat berbagai macam pola hubungan. Ada hubungan antara aku liris dengan lawan bicara di luar teks, seperti pada lagu "bunga rampai dari Bali", "patah cincin", "rayuan pulau kelapa", dsb. Contoh [12] dan [13] adalah cuplikan syair lagu "bunga rampai dari Bali" dan "patah cincin".

[12] Bunga rampai dari Bali/bunga cempaka, sruni mawar, melati/indah permai suci murni/tanda mata yang kubawa dari puri // Bunga rampai dari Bali/walaupun kini layu tak lagi wangi/namun kenang-kenangannya kan kusimpan dalam hati sanubari.

[13] Jauh di sana, di lembah raya/dekat titian di tepian sawah/namun kasihku tidak setia/pergi ke kota entah ke mana // Kata nan manis di ulang-ulang/cincin diberi kupakai sayang/namun kasihku tidak setia/patah cincin putusnya asmara.

Hubungan itu mungkin juga dengan alam semesta malam dengan rembulan dan penuh bintang, seperti pada syair lagu "cumbuan kasih di rimba lara" [14] di bawah in:

[14] Hai malam, mengapa membisu/mengapa membalut kenangan/aku tahu alammu cemerlang/dengan bunga rembulan dan bintang/merdu dengan rayuan asmara/namun bagiku hanya rimba lara // Hai malam, mengapa merajuk/biarkan daku seorang diri/kasihku hilang jauh diawan/aku hanya dengan kenangan.

Yang paling umum ditemui adalah hubungan antara aku liris dengan orang kedua yang dapat berepresentasi sebagai kekasih, pahlawan, orang yang dikagumi/diidamkan/orang yang dibenci, dsb. Untuk ini dapat diperhatikan [15] dari syair lagu "wanita" , [16] dari "selamat datang pahlawan muda", dan [17] dari "Yii" berikuit:

[15] Seindah mawar, semungil melati/dikau cemerlang wanita/semerbak wangi/sejinak merpati/dikau senandung di cita //Gerak gayamu ringan memikat hati muda teruna/mekar bersinar menyilaukan mata //halus wanita bak sutra dewangga/senyummu meruntuhkan mahkota. 
[16] Selamat datang pahlawan muda/lama nian kami rindukan dikau/bertahun-tahun bercerai mata/kini kita dapat berjumpa pula.

[17] Kalau Bung pemimpin sejati/harus Bung hati-hati/jangan Bung hanya cari kursi/untuk diri sendiri // Hilangkan hatimu yang dengki/nyahkanlah hawa nafsu korupsi/mari Bung marilah kembali/pada jalan yang suci.

Untuk menjalankan fungsi fatik ini, beberapa kata seruan fatis pengungkap kekaguman dan keakraban, penghormatan, seperti wahai, duhai, hallo, dan sapaan ungkapan vokatif, seperti Bung, Tuan, Dik, dsb. Sekadar contoh pemakaiannya terlihat dalam kutipan syair lagu "hallohallo Bandung" [18] dan "Aryati" [19], dan "sapu tangan dari Bandung Selatan":

[18] Hallo-hallo Bandung/ibu kota periangan/hallo-hallo Bandung kota kenangkenangan.......

Sekarang sudah menjadi lautan api/mari Bung rebut kembali.

[19]Dosakah hamba bermimpi kasih dengan Tuan/ujung jarimu kucium mesra tadi malam/dosakah hamba memuja dikau dalam mimpi/hanya dalam mimpi...

[20]...Diiringi kata nan merdu mesra/terima kasih Dik janganlah lupa //air mata kuberlinang sapu tanganmu kusimpan/ujung jarimu kucium serta doa kuucapkan.....

Sementara itu ada beberapa kata ganti yang digunakan untuk mengacu orang pertama, seperti [a]ku, daku, beta, dan yang paling unik adalah penggunaan kata hamba dan Tuan sebagai ungkapan kerendahanhati dalam menharapkan balasan cinta dari sang kekasih yang disapa Tuan dalam syair lagu "Aryati".

\section{Fungsi konatif}

Fungsi konatif bahasa erat berkaitan dengan apa yang diinginkan oleh aku liris terhadap lawan bicaranya, atau dengan siapa si aku liris membuat kontak. Secara linguistis tidak begitu sulit untuk mencari syair-syair lagu yang menjalankan fungsi ini karena fungsi ini ditandai dengan pemakaian kalimat-kalimat berpermarkah imperatif yang sangat jelas. Akan tetapi, akan sulit ditentukan apakah jenis-jenis kalimat lain yang perintahnya diutarakan secara tidak langsung tidak memiliki fungsi ini. Untuk yang secara tegas mengungkapkan fungsi konatif, misalnya syair lagu "jangan ditanya" dalam [8] di atas berisi permohonan agar kepergian si aku liris jangan disesali, dan hubungan di antara mereka harus diakhiri. Dalam lagu "hallo-hallo Bandung" berisi ajakan keras untuk merebut kota yang telah luluh lantak [18]. Dalam syair lagu "karangan bunga dari selatan" [21] dan [22] "melati di tapal batas" secara berturut-turut berisi pesan aku liris terhadap sang kekasih untuk meletakkan karangan bunga hasil rangkaiannya bila kelak aku liris gugur di medan laga, dan menghimbau para Srikandi muda untuk membangun kembali kampung halamannya setelah merebut kemerdekaan. 
[21] Bunga terkarang indah permai/pengikat tali jiwaku/kurnia dari putri suri/tanda bakti darimu //Bunga dijalin rempah rempai/ dihiasi warna warni/tercantum di dalam kalbuku/bunga ciptaan dewi // Seruan masa datang bagimu/panggilan ibu pertiwi/kan kukenang bunga karanganmu/kelak menabahkan hati //Andai kata aku kan gugur/aku berpesan padamu/hiaskan di batu nisanku/karangan bunga darimu.

[22] Engkau gadis muda jelita, bagai sekuntum melati/Engkau sumbangkan jiwa raga di tapal batas Bekasi/engkau dinamakan Srikandi, pendekar putrisejati/engkau turut jejak pemuda, turut mengawal negara // Oh pendekar putri yang cantik/dengarlah panggilan ibu/sawah ladang rindu menanti/akan sumbangan baktimu //Duhai putri muda remaja, suntingan kampung halaman/kembali ke pangkuan Bunda, berbakti kita di ladang.

Yang menarik adalah gaya syair lagu "pilihan menantu". Dalam syair lagu ini terjadi dialog konatif antara sang anak gadis [+] dengan ibundaya [x] dan para calon menantu [-] dari berbagai profesi, seperti dalam [23] berikut walau tidak jelas secara implisit apakah sang anak memilih orang berprofesi tukang beca. Sang gadis menasihati ibunya, sang ibu meminta anaknya menegaskan pilihannya, dan para calon menantu memprovokasi kehebatannya untuk dijadikan menantu pilihan.

[23]+ Oh ibu-ibu sabarlah dulu janganlah nafsu pilih menantu/harus teliti dan hati-hati aku tak ingin menyesal di belakang hari

- Pilihlah aku kapten udara helikopterku emas kawinnya.

- Pilihlah aku mayor lautan kapal selamku tidak ada yang mlawan

+ Kapten udara memang jempolan, hebat sekali mayor lautan, Sayangilah sayang mereka itu bukan pilihan idaman hatiku Bu.

- Pilihlah aku saudagar muda kota Jakarta ane yang punya.

- Pilihlah aku raja wartawan ke hollywood kita pergi lain bulan

+ Saudagar muda aku emoh Bu walau dunia dia yang punya.Aku tak ingin pada wartawan takut rahasia dapurku masuk koran

- Pilihlah aku kandidat duta bulan madumu Kutub Utara

- Pilihlah aku arsitek kaya rumah gedong besar uang kuncinya.

+ Kandidat duta Kutub utara takutlah beku asmara beta. Arsitek kaya "I don't like Mama" silau mukaku si dia banyak lagunya.

$x$ Habis yang mana pilihanmu Dik yang ini ogah yang itu ogah.

- Pilihlah aku manusia biasa walau emas kawinnya hanyalah beca.

\section{KESIMPULAN}

Dari uraian di atas jelas bahwa sebuah wacana apa pun jenisnya akan selalu menjalankan berbagai fungsi bahasa, dan tidak mungkin hanya melaksanakan fungsi bahasa yang tunggal. Hanya saja berbagai fungsi yang dibawa atau dijalankan itu ada yang lebih bersifat diominan dibandingkan fungsi-fungsi yang lain. Demikian halnya syair-syair lagu Ismail Marzuki secara 
dominan menjalankan fungsi puitik bahasa agar semua fungsi-fungsi bahasa yang lain, seperti fungsi emotif sebagai sarana pengungkapan perasaan, fungsi referensial sebagai sarana pengacuan, fungsi fatis sebagai sarana pembinaan hubungan, dan fungsi konatif sebagai sarana realisasi direktif untuk pemenuhan perintah, ajakan, permohonan, dsb dapat dipersepsi secara estetis. Semua syair lagu Ismail Marzuki berbicara tentang sesuatu atau dunia di luar bahasa, bukan tentang bahasa itu sendiri sehingga fungsi bahasa yang bersifat metalingual tidak ditemui di dalamnya.

\section{DAFTAR PUSTAKA}

Browns, Gillian \& George Yule. 1983. Discourse Analysis. Cambridge University Press.

Buhler, K. 1934. Sprachtheorie. Gustav Fisher: Jena.

Halliday, M.A.K. 1970. "Language Structure and Language Function". in New Horizons in Linguistics. John Lyons [Ed.]. Harmondsworth, Middx: Penguin Books.

Holmes, Janet. 1995. An Introduction to Sociolinguistics. London: Longman.

Hymes, Dell. 1974. Foundation in Sociolinguistics: An Ethnographical Approach. Philadelphia: University of Pennsylvania Press.

Jakobson, Roman. 1966. "Closing Statement: Linguistics and Poetics", Dalam Style in Language.Thomas A. Sebeok [Ed.]. Massachusset: The MIT Press.

Kadarisman, Effendi. 2009. "Puitika Linguistik Pasca-Jakobson: Tantangan Menjaring Makna Simbolik". Dalam Mengurai Bahasa Menyibak Budaya. Universitas Negeri Malang. HIm. 52-83.

Leksono, Ninok. 2014. Ismail Marzuki: Senandung Melintas Zaman. Jakarta: Kompas.

Lyons, John. 1970. Semantics. Vol. I, Cambridge: Cambridge University Press.

Pradopo, Rachmat Djoko. 2012. Pengkajian Puisi. Cetakan XIV. Yogyakarta: Gadjah Mada University Press.

Wijana, I Dewa Putu. 2017. "Kebebasan Penyair: Yang Dicapai dan Yang Dikorbankan". Dalam Mencari Formula Baru Kritik Sastra Indonesia. Sudibyo \& Saiful Anwar [eds]. Yoguyakarta: interlude. Hlm. 14-29.

Yosa, Rinda. 2016. Metafora Wanita pada Lagu-lagu Karya Ismail Marzuki. Skripsi Sarjana Fakultas Ilmu Budaya Yogyakarta.

\section{SUMBER DATA}

Leksono, Ninok. 2014. Ismail Marzuki: Senandung Melintas Zaman. Jakarta: Kompas.

Redaksi Cemerlang Publishing. 2017. Lagu Wajib Nasional dan Daerah. Jakarta: Cemerlang Publishing. 